\title{
O PACIENTE DE ACIDENTE VASCULAR CEREBRAL E OS ASPECTOS DE ENFERMAGEM EM REABILITAÇÃO
}

\author{
Celina A. Camargo*
}

RBEn/05

CAMARGO, C.A. - O paciente de acidente vascular cerebral e os aspectos de enfermagem em reabilitação. Rev. Bras. Enf.; $28: 35-42,1975$.

\section{INTRODUÇÃO}

Na medida em que os recursos para combate às doenças e manutenção da saúde aumenta, espera-se também que aumente a expectativa de média de vida da população brasileira. Nesta contingência, é de se esperar que modifique o panorama epidemiológico, em relação à incidência das moléstias mais freqüentes entre indivíduos de meia idade e de idade avançada.

Entre estas doenças, encontram-se os tumores e as moléstias degenerativas e vasculares, que podem ser vencidas, superadas ou tornarem-se crônicas, ocorrendo, muitas vezes em conseqüência, lesões incapacitantes como as hemiplegias.

Diante desta perspectiva, pode-se esperar um aumento progressivo do número de hemiplégicos pelo menos enquanto não se dispuser de medidas profiláticas eficientes em relação às doenças que as ocasionam.
Entretanto, medidas profiláticas podem ser adotadas a fim de: a) não agravar as condições físicas decorrentes da hemiplegia; b) proporcionar meios para que, embora com limitações, o hemiplégico se reintegre na família e na sociedade.

Estas medidas se referem aos programas de Reabilitação, que é um processo dinâmico e total e que procura abordar todas as necessidades do paciente a fim de ajudá-lo a reintegrar-se no meio a que pertence.

A Enfermagem como profissão, e mais especificamente a enfermeira com conhecimento da especialidade, tem muito a contribuir, participando da equipe de reabilitação nos programas para hemiplégicos.

O objetivo deste trabalho é focalizar os aspectos da Enfermagem em Reabilitação que, se adotados, podem concorrer para evitar o agravamento das con-

* Diretor da Divisão de Reabilitação Profissional de Vergueiro - Hospital das Clínicas SP. 
CAMARGO, C.A. - O paciente de acidente vascular cerebral e os aspectos de enfermagem em reabilitação. Rev. Bras. Enf.; 28 : 35-42, 1975.

dições físicas do paciente e ajudá-lo na sua reintegração social.

Limita-se este trabalho aos objetivos acima citados.

A assistência ao paciente na fase imediata à instalação do processo é tão complexa que justificaria, por si só, uma abordagem especial.

\section{HEMIPLEGIA}

O termo hemiplegia é apenas descritivo, significando paralisia de uma metade do corpo. É portanto, a sequela de uma patologia que pode estar localizada em uma ou algumas áreas do sistema nervoso central, e de acordo com Deaver (1958), até o nível da $5 .^{2}$ vértebra cervical. Assim focalizada, parece ser mais fácil compreender quantos e quão diferentes perdas funcionais podem ocorrer, devidas à hemiplegia. E em relação a estas perdas que a enfermeira deve atuar. Conhecendo-as poderá compreender quantas modificações podem ocorrer com o paciente e compreender também as suas reações, diante destas modificações.

As alterações físicas-funcionais e psicológicas mais comumente encontradas nos hemiplégicos são:

- paresia ou paralisia de um lado do corpo;

- alterações no processo de alimentação e eliminação;

- alteração no processo de comunicação pela linguagem;

- dificuldades visuais e auditivas;

- alteração do esquema corporal;

- alterações do comportamento;

- dificuldade para movimentar-se fazer higiene corporal, vestir-se e alimentar-se; família.
POSTURA

Devido à paralisia, a postura do paciente fica alterada. O braço do lado afetado tem tendência à abdução e rotação interna; a perna fica em rotação externa, em abdução, com ligeira flexão de quadril; acentuada flexão de joelho e dorso-flexão do pé. Esta postura, se não for corrigida, poderá levar a deformidades sérias que poderão comprometer a recuperação do paciente.

A primeira medida portanto, é corrigir a postura para evitar o aparecimento de deformidades, atuando sobre as causas determinantes, que são: por um lado, a ação da gravidade sobre a parte paralisada e por outro, a ação dos músculos hígidos que nada sofreram, sobre os paralisados.

Para diminuir a ação da gravidade, procura-se dar apoio às partes afetadas, da seguinte forma:

a) quando o paciente está em decúbito dorsal, utiliza-se um travesseiro baixo que não force a flexão do pescoço e que apoie também ombros; cabeça e ombros devem ficar no mesmo alinhamento. Coloca-se um coxim ou travesseiro ao lado do corpo do paciente, fazse ligeira abdução do braço lesado apoiando-o sobre o travesseiro. Na mão do paciente, coloca-se um pequeno rolo, leve e firme, para manter os dedos em abdução ou polegar em oponência.

Em relação à perna, pode ser utilizada uma goteira de material leve e forrada com espuma. Entretanto, como nem sempre dispõe-se destas goteiras, alinha-se os membros inferiores em relação ao eixo da bacia e coloca-se um rolo de lençol para manter a posição do membro afetado. Este rolo deve ser feito com lençol dobrado no sentido da sua extensão. A largura da dobra deve corresponder à distância entre a crista ilíaca até a região do "plateau" tibial. Coloca-se uma extremidade do lençol dobrado sob a nádega e coxa do paciente 
CAMARGO, C.A. - O paciente de acidente vascular cerebral e os aspectos de enfermagem em reabilitação. Rev. Bras. Enf.; 28 : 35-42, 1975.

esticando-o bem, inicia-se o rolo pela outra extremidade do lençol, com as dobras voltadas para a face do colchão. São três os fatores que devem ser observados para que este rolo atinja seu objetivo de oferecer apoio à musculatura paralisada e permitir posição adequada do membro:

- o comprimento do lençol sob a coxa do paciente

- a tensão do lençol ao se fazer o rolo

- a tensão do rolo em contato com o paciente

Para apoiar o pé que está em dorsoflexão, coloca-se uma prancha de madeira entre o colchão e a peseira da cama, deixando-se um pequeno espaço entre ambos. Apoia-se o pé na tábua protegida com fronha ou lençol de tal forma que o calcâneo fique no espaço livre entre a tábua e o colchão.

Para o paciente descansar, deve-se mudá-lo de posição muitas vezes ao dia. Entretanto, nas posições ventral e lateral, os efeitos da gravidade e dos músculos atuantes sobre os músculos paralisados devem ser evitados, observandose os mesmos princípios de apoio e manutenção da postura das partes lesadas.

A mudança de decúbito deve ter início tão precocemente quanto o estado do paciente permitir. Se o paciente não está inconsciente e o médico concordar, a movimentação deve ser iniciada no $2 .^{\circ}$ dia após a instalação do processo. Enquanto não é permitida a mudança de decúbito, pode-se pelo menos mudar a posição do braço afetado, colocando-se um travesseiro ao lado da cabeça do paciente e fazendo abdução do braço, rotação externa, flexão do cotovelo e supinação do antebraço. O braço é colocado sobre o travesseiro, para que o paciente descanse nesta posição.

Sendo a escara uma complicação relacionada com a posição estática do paciente no leito, é bom lembrar que a mudança de decúbito é fator primordial na prevenção das mesmas. Elas devem ser evitadas porque, além dos outros transtornos que acarretam, dificultam a manutenção da postura adequada do paciente no leito.

\section{ALIMENTAÇÃO E ELIMINAÇÃO}

A alimentação do paciente deve ser equilibrada em calorias, para evitar que ele ganhe peso e encontre futuramente, dificuldade na realização de atividades que requeiram maior esforço.

A alimentação não deve provocar alteração no funcionamento intestinal, tais como: constipação e diarréia; deve, tanto quanto possível, ser individualizada, de acordo com a aceitação e reação orgânica do paciente.

Quando a paralisia atinge nervos faciais, ainda que levemente, pode ficar alterado o processo de mastigação e deglutição. Ao se reintroduzir alimentos sólidos na refeição do paciente ensiná-lo a: colocar o alimento na boca do lado oposto à lesão; mastigar bem $\mathbf{e}$ devagar; deglutir desse mesmo lado, ajudando tanto quanto possível com a língua. Se não houver o cuidado de usar apenas o lado não afetado para a mastigação e deglutinação, pode ocorrer que os alimentos fiquem retidos sob a língua do lado paralisado e o paciente rejeite a refeição.

O processo de eliminação também pode ficar alterado portanto, a enfermeira deve procurar saber dos familiares ou do próprio paciente, se isto for possível, quais eram os padrões anteriores de eliminação.

Em relação à eliminação vesical, deve-se oferecer condições para que o paciente esvazie a bexiga nos horários habituais anteriores à lesão.

Procede-se da mesma forma em relação à eliminação intestinal. Caso haja necessidade de ajudar com supositório ou outro processo terapêutico, o horário 
CAMARGO, C.A. - O paciente de acidente vascular cerebral e os aspectos de enfermagem em reabilitação. Rev. Bras. Enf.; 28 : 35-42, 1975.

para realizar a prescrição médica deve ser calculado em relação ao tempo que o medicamento leva para fazer efeito e o horário habitual do funcionamento intestinal do paciente; portanto, se o medicamento leva uma hora para fazer efeito e o paciente tinha por hábito esvaziar o intestino logo após a $1 .^{\text {a }}$ refeição, o medicamento deve ser ministrado uma hora antes da $10^{\mathrm{a}}$ refeição.

Os primeiros objetivos de manter um bom funcionamento intestinal e vesical são:

- proporcionar padrões regulares de eliminação

- evitar incontinência, constipação e impacção

- manter o tônus vesical

- evitar irritação e/ou escarificação da pele

- aliviar tensão emocional.

Com sistematização e perseverança, a enfermeira poderá ajudar o paciente a recuperar os hábitos anteriores e alcançar os objeivos mencionados.

\section{COMUNICAÇÃO PELA LINGUAGEM}

Um dos mais sérios problemas que pode resultar de um distúrbio da função cerebral é a afasia e nós a identificamos pela dificuldade do paciente em comunicar-se pela linguagem. Como a comunicação com o paciente é de grande importância, abordar-se-á alguns aspectos da afasia, que parecem ser de fácil identificação pela enfermeira.

A linguagem se processa pela habilidade do indivíduo em falar, escrever, ler e compreender o que ouve ou lê. $\mathrm{Na}$ afasia, uma ou algumas destas habilidades podem estar alteradas.

Há distúrbios cerebral que afeta 0 processo de formular idéias e transformá-las em palavras ou ainda de compreender o significado da combinação de frases complexas, apesar de ser capaz de compreender a palavra ou frase simples.
Outras vezes, o paciente apresenta inabilidade em reconhecer a palavra escrita ou falada, mesmo sem apresentar distúrbio auditivo ou visual-agnósia. Outra alteração refere-se à inabilidade de utilizar os músculos da fonação, embora não apresente paralisia destes músculos-apraxia.

Apesar de apresentar um ou alguns destes distúrbios, o paciente precisa ser atendido e, espera-se, compreendido. A observação das expressões faciais e dos gestos do paciente, além de alguns comportamentos por parte da enfermeira,

1 - Adota-se um comportamento que demonstre ao paciente que a dificuldade apresentada não é devida à deficiência intelectual, mas somente a uma dificuldade em expressar e compreender os símbolos da linguagem. $O$ fato dele não ser capaz de dizer o nome dos objetos que o rodeiam não significa que ele desconheça o uso e a função dos mesmos. Igualmente o fato do paciente não saber dizer o nome dos parentes e amigos não significa que ele não os reconheça. Presume-se que sua bagagem de informações, conhecimentos e compreensão está intacta. A sua deficiência refere-se apenas à falta de habilidade de comunicar pela linguagem as coisas que ele sabe.

2 - Evita-se cuidadosamente tratar o afásico com excessiva pena, de um lado ou com impaciência, de outro. Deve-se tratá-lo como um adulto normal, sob todos os aspectos, exceto quanto aos aspectos físico e à dificuldade de comunicação que ele apresenta.

3 - Encoraja-se o paciente a tornarse o mais auto-suficiente possível.

4 - Estimula-se o paciente a falar, porém não se impõe que ele fale.

Faz-se todo esforço para entender o que ele está tentando expressar, talvez diga palavras sem nexo mas que apresente sentido, pode falar erroneamente ou falar palavras obcenas e profanas; pode pronunciar algumas palavras cor- 
CAMARGO, C.A. - O paciente de acidente vascular cerebral e os aspectos de enfermagem em reabilitação. Rev. Bras. Enf.; 28 : 35-42, 1975.

retas e em seguida outras incoerentes. Este comportamente não deve ser interpretado como resultado de ignorância, distúrbio mental, teimosia ou vulgaridade. Esta é a forma típica do resultado das tentativas do afásico para expressar-se pela linguagem falada.

5 - Se o paciente tem dificuldade para expressar-se, evita-se fazer perguntas cuja resposta possa ser sim ou não, porque ele pode dizer sim quando quer dizer não e vice-versa .

6 - Encoraja-se o paciente a comunicar-se pela linguagem sob qualquer forma que ele demonstre ser capaz: falando, lendo ou escrevendo. Se ele não é capaz de falar o que deseja mas, pode repetir depois de ouvir, ajuda-se o paciente a expressar-se desta forma. Se ele não é capaz de falar mas é capaz de escrever e ler, este deve ser o seu processo inicial de comunicação.

7 - Deixa-se entretanto que o paciente se esforce por dizer a palavra desejada, antes de ajudá-lo. Antecipar-se ao paciente é tirar-lhe a oportunidade de conseguir expressar-se sem auxílio. A comunicação deve, entretanto, ser interrompida delicadamente aos $1 .^{\circ}$ sinais de fadiga demonstrados pelo paciente.

8 - Cumprimenta-se o paciente pelo esforço e sucesso alcançado.

9 - Fala-se com o paciente vagarosa e distintamente, fazendo pausas freqüentes. Fala-se pouco, usando-se frases simples.

10 - Eecessário identificar se a dificuldade do paciente é em compreender as pessoas ou em expressar-se procurando ajustar apropriadamente a forma de comunicar-se com ele.

11 - Procura-se ajudar a família e amigos a compreender a dificuldade do paciente e a adotar a forma considerada mais adequada para comunicar-se com ele.

\section{DIFICULDADES VISUAIS}

Embora não tão acentuadas, como as deficiências de comunicação, o paciente pode apresentar algumas dificuldades visuais e a mais freqüente é a hemianopsia. A percepção cinestésica da verticalidade, referem alguns autores, também pode estar prejudicada. Quando a percepção vertical está alterada, o paciente tem dificuldade em perceber pela visão, objetos na vertical, e pode por exemplo ver a parede inclinada.

Lembrando-se que estas alterações podem ocorrer, deve-se dispor o leito em posição que facilite ao paciente enxergar a maior parte do aposento. A mesa de cabeceira, a cadeira e outros utensílios que por ventura existam no quarto, devem ser colocados em posições que possam ser melhor visualizados pelo paciente. Ao abordá-lo, faz-se pelo lado não afetado, principalmente para dar-lhe algum cuidado ou falar-lhe.

\section{ALTERAÇÃO DO ESQUEMA CORPORAL}

Com uma parte do corpo paralisada, o esquema corporal do paciente poderá ficar afetado. Até então ele tinha consciência do seu corpo como um todo, das diferentes partes do seu corpo, da sua postura e dos seus movimentos no meio ambiente.

Após a paralisia, os seus membros já não reagem ao estímulo e à movimentação como anteriormente. Agora ele já não dispõe de dois braços para abraçar, de duas pernas para andar. O seu corpo já não funciona de acordo com o esquema que geralmente corresponde à imagem corporal que o indivíduo tinha de si mesmo. Entretanto, para que o paciente perceba que não perdeu a integridade corporal, embora não possa movimentar-se livremente, fá-lo-emos passar muitas vezes por dia, a mão do lado não afetado, sobre o lado afetado, igualmente, ele deverá passar o pé do lado 
CAMARGO, C.A. - O paciente de acidente vascular cerebral e os aspectos de enfermagem em reabilitação. Rev. Bras. Enf.; $28: 35-42,1975$.

não afetado sobre a perna e o pé afetados. Tăo precocemente quanto possível, faz-se o paciente levantar-se e secar-se; adotando estas medidas, ajuda-se a evitar que o esquema corporai do paciente se deteriore, o que poderá interferir negativamente no seu proces. so de Rabilitação.

\section{ALTERAÇÕES DO COMPORTAMENTO}

É bastante comum às pessoas hemiplégicas algumas alterações de compor. tamento. O paciente pode apresentar esquecimentos e associações com acontecimentos emocionais dolorosos e perdas do passado, resultando disto uma volta à imaturidade infantil.

Outra reação comum é de agressividade nas mais diversas formas e que pode manifestar-se em relação a si mesmos ou a terceiros.

Também é bastante freqüente a instabilidade emotiva nestes pacientes, levando-os a chorar ou a rir sem estímulo correspondente.

Estas alterações podem ser temporá. rias, enquanto se processa o ajustamen. to psicológico. Ajuda-se o paciente aceitando-se e compreendendo suas infantilidades e seu comportamento irracional e agressivo, como uma fase natural do seu ajustamento à incapacidade.

DIFICULDADE PARA MOVIMENTARSE FAZER HIGIENE CORPORAL, VESTIR-SE, ALIMENTAR-SE E AJUSTAR-SE A FAMILIA

Embora o paciente tenha dificuldade para realizar estas atividades, deve-se tentar torná-lo capaz de executá-las sem auxílio ou com o mínimo de auxílio necessário.

- Movimentação

Desde que o médico libere a movimentação, ensina-se o paciente a movimentar-se no leito para mudar de posição. Faz-se com que ele cruze o braço não lesado sobre o tórax e segure a borda oposta do colchão. A seguir puxa o colchão com a mão, flexiona a perna e o pé não afetados contra o colchão e gira o corpo sobre a parte lesada.

Para virar-se sobre o lado oposto, segura a borda do colchão do lado não lesado do corpo, flexiona a perna não paralisada, colocando o pé sob a perna paralisada, empurra o colchão com o pé e puxa a perna lesada sobre a não lesada. Inicialmente, ajuda-se o paciente neste procedimento.

Para sentar-se na cama, ensina-se o paciente a pegar o braço lesado com a mão funcionante, fletir o cotovelo e cor locar o membro lesado sobre o tórax. Em seguida, coloca o pé não lesado sob a perna lesada e, nesta posição, escorrega as 2 pernas para a borda do colchão. Depois que os pés estiverem fora da cama, faz flexão do cotovelo, segura na borda do colchão e apoiando-se sobre o cotovelo e a mão, eleva o tórax até, sentar-se. Para ajudá-lo inicialmente, pode-se colocar as mãos logo acima dos joelhos do paciente, para estabilizar as pernas e ficar mais fácil para ele sentar-se.

Se o paciente tem grande dificuldade e não consegue sentar-se sem maior auxílio, depois que ele já trouxe as pernas para a borda da cama, pelo lado não lesado passa-se uma das mãos pela face posterior do pescoço, e a outra sob as pernas do paciente, pelo lado não lesado.

Pede-se lhe que segure no ombro de quem o auxilia e, em movimentos coordenados, ajuda-o a sentar-se na cama.

Para deitar, ensina-se o paciente a colocar o pé não lesado sob a perna lesada, segura a borda do colchão na altura do quadril e lentamente vai fletindo o cotovelo e, pressionando a bacia contra o colchão, eleva as pernas e deita-se lentamente.

Atuando de forma progressiva ajudase o paciente, depois que está sentado na borda da cama a passar para a ca- 
CAMARGO, C.A. - O paciente de acidente vascular cerebral e os aspectos de enfermagem em reabilitação. Rev. Bras. Enf.; $28: 35-42,1975$.

deira de rodas, que deve ser colocada ao lado da cama. Pede-se-lhe que coloque a mão sobre o nosso ombro. Segura-se o paciente à altura da cintura e com o joelho direito bloqueia-se o joelho não lesado. Levanta-se o paciente, gira-se o seu corpo sobre a perna boa e ajuda-o a sentar na cadeira de rodas.

\section{HIGIENE CORPORAL}

Já mencionamos anteriormente que tal procedimento, tanto quanto possível deve contar com a participação do paciente. Esta é uma atividade que ele realizava habitualmente, sem depender de auxílio e ele precisa recuperar a independência na sua realização. $O$ paciente pode sentir-se constrangido por precisar de auxílio para fazer a sua higiene após a evacuação, da mesma forma que ele pode sentir-se envergonhado de precisar que alguém o lave ou mesmo que lave sua prótese dentária, se ele a usa.

Orienta-se a proceder a sua higiene corporal enquanto acamado e, na medida que ele pode movimentar-se e sair do leito, atuando da mesma forma que se procedeu para fazê-lo sentar-se na cadeira de rodas, ensina-se a sentar em uma cadeira colocada no local do chuveiro, onde faz a limpeza corporal e retorna a cadeira de rodas.

Adota-se o mesmo princípio de apoio à região lombar e bloqueio do joelho não lesado, para ensiná-lo a utilizar o sanitário.

Sempre que o paciente for sentar-se, coloca-se uma tipóia para apoiar o braço lesado.

\section{VESTIR-SE}

Remover as roupas e vestir-se é outro aspecto do cuidado pessoal que fica pre- judicado devido à hemiplegia. Recuperar a independência nestas atividades é de grande importância para a valorização pessoal e social do paciente. O fato dele escolher suas roupas, trocá-las quando desejar, preparar-se com roupas próprias para dormir, como as demais pessoas, ajuda-o a sentir-se dentro do padrão normal do comportamento de pessoas adultas.

Ensina-se o paciente a colocar a roupa, vestindo primeiro o lado lesado e depois o lado não lesado. Para vestir blusa ou camisa, veste o lado lesado até o ombro e coloca o braço sobre o colo e veste o outro lado. Para despir, desce a roupa até o cotovelo do lado lesado, despe o lado não lesado e acaba de puxar a camisa ou blusa que ficou retida no braço lesado.

Observando o mesmo princípio de vestir primeiro a parte lesada e depois a outra, ensina-se o paciente a vestir as calças e roupas interiores. Para despirse, iniciar pelo lado não lesado.

Para calçar meias e sapatos, orienta-se o paciente a cruzar a perna lesada sobre a não lesada, calçar-se e descalçar-se.

Embora não tenha sido mencionado, o paciente se cansa facilmente, por esta razão, as atividades devem ser ensinadas dentro do limite de tolerância física e da habilidade de seu aprendizado. Este limite deve ser identificado e respeitado. O paciente cansado torna-se irritado e pouco cooperador.

Acreditamos que, se os aspectos de enfermagem aqui focalizados forem adotados, muito ajudarão na recuperação do paciente.

As atividades, se iniciadas precocemente e ao mesmo tempo em que se inicia a prevenção de deformidades, muito contribuirão para ajudar o paciente a reorganizar o conhecimento das diversas partes do seu corpo e a diminuir alguns problemas da imagem 
CAMARGO, C.A. - O paciente de acidente vascular cerebral e os aspectos de enfermágem em reabilitação. Rev. Bras. Enf.; 28 : 35-42, 1975.

corporal. Ajudando-se a evitar deformidades, por vezes dolorosas como o ombro congelado, não só a dor é evitada como a imagem física que tanto o paciente preza pode ficar conservada. Respeitando-se e procurando-se conservar esta imagem através da prevenção de defor- midades, procurando-se compreender as dificuldades de comunicação, aceitando-se as mudanças de comportamento como transitórias e normais em relação às condições do paciente, pode-se dizer com segurança que contribuiu-se no seu processo de Reabilitação.

\section{FOLHETOS:}

BONNER, Charles D., M.D. - Prognostic evaluation for Rehabilitation of patients with strokes. Geriatrics, Vol. 14, pp. 424-428, July, 1959.

COVALT, Donald A., M.D. - Early Management of a Patient with a stroke Medical Times April, 1958.

KNAPP, Miland E., M.D. and OWEN, Richard R., M.D. - Rerabilitation of the he- miplegic patients. Geriatrics vol. 14, pp. 306-311, May, 1959.

RUSK, Howard A., M.D. - Hemiplegia and Rehabilitation Bed positioning and transfer. Procedures for the hemiplegic American Rehabilitation Foundation. 1964.

Self-care and homemaking for the hemiplegic. American Rehabilitation Foundation. 1964. 